\title{
Trends in the Enterprise Resource Planning Market Landscape
}

\author{
Shadrack Katuu \\ Department of Information Science \\ University of South Africa, Pretoria, South Africa
}

skatuu@gmail.com

\begin{abstract}
The purpose of this article is to provide a brief discussion of ERPs, including how they can be defined, their component parts, and the evolution of technologies since the 1940s. The article then offers a general overview of the current ERP vendor market landscape based on academic journals and industry reports. The article's methodological approach is a review of both academic literature and industry expert reports, which the author performed to trace trends within the landscape. Results of the analysis demonstrate that the rapidly evolving market landscape dates back at least six decades, and there are many large, longstanding ERP vendors. Yet, opportunities like cloud computing may result in niche products in existing industry players or through start-ups. These include trends such as the Fourth Industrial Revolution, artificial intelligence, blockchain technology as well as computing. Nonetheless, it remains to be seen how they will impact the ERP market.

Keywords: artificial intelligence, blockchain technology, cloud computing, cloud ERPs, digital disruption, ERP vendor market, Fourth Industrial Revolution, postmodern ERPs
\end{abstract}

\section{Introduction}

The enterprise resource planning (ERP) phenomenon has been a reality for many institutions over several decades. ERP is the integrated management of institutional activities mediated by technology [1]. According to Greengard [2], an ERP system is at the centre of an institution, tackling core tasks of managing and integrating business processes in real-time. Not all global institutions have implemented any ERP systems. However, many institutions require integrated enterprise wide functionality in areas such as accounting, sales, order management, customer relationship management (CRM), and supply chain management (SCM). Van Decker, Anderson, and Leiter [3] argued that ERPs continue to be the largest category of enterprise software expenditures in institutions.

Working professionals have endeavoured to ensure disciplinary theories and methodologies are in step with the rapidly evolving realities of the digital environment [4] - [5]. Numerous researchers have examined ERP systems development as well as implementation challenges and future [6] - [10]. However, it is rare to find 
publications that give a general landscape of the ERP software vendor industry. Dahlén and Elfsson [11] investigated global ERP in 1999, pointing out eight companies at the time. Almost two decades later, when examining the emergence of the ERP software market, Erkut [12] based the discussions on one company that was a pioneering innovator in the market. Therefore, this article's contribution to academic discourse is to provide an overview of the current ERP vendor market landscape as well as trace current and emerging trends in that landscape.

\section{Methodology and Approach}

This article's methodological approach is a review of both academic literature and industry expert reports. This review explores relevant sources in order to provide a brief discussion of ERPs, including how they can be defined, their component parts, and the evolution of technologies since the 1940s [6], [13]. The article then offers a general overview of the current ERP vendor market landscape. There are various criteria that institutions could use to categorize ERP vendors, including market share, geographical coverage of their client base, historical background, and expansion patterns. However, this article uses two industry experts: Panorama Consulting and eWeek magazine's author, Samuel Greengard. Panorama Consulting is an information technology (IT) service company that specializes in business management and ERP consulting. Samuel Greengard has almost two decades of experience as an IT editor and writer. Together, their reports provide an expansive view rather than a deep analysis of the market. This article then discusses the current and emerging trends in the ERP market, concentrating on cloud computing, Fourth Industrial Revolution, artificial intelligence, and blockchain technology. The article concludes by reflecting on limitations and opportunities in the developing research on ERPs.

\section{Defining ERPs}

Readers can understand an ERP as both a concept that involves the integration of business processes as well as a system that, at its core, has an integrated database and several modules that cover various functional areas [14], [15]. The ERP may have one or more modules providing cross-organization integration of information, managing, and integrating core business processes in real-time [16]. These modules include the following:

1. Billing

2. Distribution

3. Finance

4. Human Resources

5. Logistics

6. Order Management

7. Procurement

8. Production

9. Project Management

10. Sales 


\section{Scheduling \\ 12. Shipping \\ 13. Supply Chain Management}

For this reason, ERP systems are more than just mere technological artefacts. They are core platforms designed to support and leverage the capabilities of the tools and processes used by an organization [16]. In this sense, they are at the centre of everything an organization does, providing it the opportunity to adopt standardized practices and to have the potential to enhance operational efficiency, accountability, and organizational performance [14]. By managing and coordinating data and workflows between and among these components, it is possible for an organization to improve processes, trim costs, and achieve a more streamlined and effective business framework [2].

ERP platforms and concepts trace their genesis in the early years of computing to the 1940s. They have their immediate precursors as integrated control (IC) packages of the 1960s and the material resource planning (MRP) systems of the 1970s and 1980s. Between the 1990s and 2000s, ERPs and extended ERPs initially had monolithic architecture. They then moved toward multiple platforms in the advanced ERPs of the 2010s [16], [17]. In the 2000s, traditional ERP systems began expanding their footprint to include CRM, human capital management (HCM), enterprise asset management, product lifecycle management, product information management, product data management, quality assurance, manufacturing execution systems, SCM, transportation management systems, and warehouse management systems [18].

In the mid-2010s, Gartner, a global research and advisory firm, coined a new term of postmodern ERPs that they saw as more agile and outward facing than previous ERP iterations [19]. A postmodern ERP is described as a technology strategy that "automates and links administrative and operational business capabilities (such as finance, human resources, purchasing, manufacturing, and distribution) with appropriate levels of integration that balance the benefits of vendor delivered integration against business flexibility and agility" [20]. In this sense, a postmodern ERP is a more federated, loosely coupled environment than previous ERP iterations, with all or most of its functionality sourced as cloud services or business process outsourcers [19]. In a postmodern ERP, institutions can deploy modules or applications as complementary systems to support a postmodern ERP strategy, or embed or integrate them with a core ERP system [18].

The rapid technological development that took place between the 1990s and the 2020s resulted in institutions with ERPs implemented in the 1990s facing a technological crisis. On the one hand, modern institutions, including both multinational companies [21], [22], and small and medium size enterprises [23], increasingly required integrated enterprise applications. On the other hand, traditional ERPs had core legacy systems that were inflexible and unable to keep up with rising demands. Therefore, they were faced with the challenge of upgrading these applications.

According to Møller [24], ERP research prior to 2000 consisted of two strands. The first strand related to ERP success and failure research and ERP implementation [6], [25]. The second strand looked at ERP technology as an enabler of business 
process reengineering [26]. A wide array of literature discusses challenges in implementing ERP: technical implementation challenges and organizational implementation challenges [27]. One of the technical implementation challenges is error in the choice of ERP software [27]. The choice of ERP software is a strategic decision that requires a large number of factors to be taken into consideration [28]. One of the considerations is a thorough understanding of the choice of ERP software products available in the market. The next section provides an overview of the modern ERP market landscape.

\section{ERP Vendor Market Landscape}

According to She and Thuraisingham [29], the ERP market landscape in the early 2000 s included a wide variety of vendors. For instance, there were about 50 established vendors and a few more emerging smaller and medium size ERP vendors, including third party developers competing for the ERP market [30]. Due to historic reasons, these vendors had a specialty in a particular module area, such as Baan in manufacturing, PeopleSoft in HR management, SAP in logistics, and Oracle in financials [30].

At that time, some of the most consequential and tectonic changes took place in the market. For instance, in 2004, Oracle acquired PeopleSoft and JD Edwards, gaining approximately $22 \%$ of the ERP market share [29], [31]. By 2005, Sage had revenue of $\$ 1.4$ billion in the ERP market, claiming a 6\% market share as the third largest ERP vendor. In 2005, SAP had 26\% of CRM market share, $29 \%$ of ERP market share, and $19 \%$ of SCM market share by total software revenue [29].

According to Zare Mehrjerdi [32], the major ERP players in 2010 included SAP, Oracle, and Baan. Over the years, several ERP companies have come and gone. Others have maintained or strengthened their positions through mergers and acquisitions. There are different ways of laying out the current landscape. This section outlines two such ways by two industry experts, Panorama Consulting, and eWeek magazine's author, Samuel Greengard.

Panorama consulting [18] categorized ERP systems into Tier I, Upper Tier II, Lower Tier II, and Tier III based on factors such as target organization size, vendor revenue, target number of users, and other factors such as functional complexity (Table 1).

In Table 2, Greengard (2019) used varied criteria to identify a list of 10 ERP software providers, their flagship products, deployment, and headquarters. Table 2 also provides ratings based on the assessment of various industry reports.

Tables 1 and 2 demonstrate how vast the ERP industry is by showing at least thirteen current ERP vendors and some of their flagship products. However, the tables remain static illustrations that do not reveal the dynamic changes over time. Therefore, any organization that uses such resources for decision making needs to be cognizant of nuanced dynamism. For instance, regarding the issue of deployment, Panorama Consulting [33] noted $67 \%$ of the institutions had on-premises ERP software, $27 \%$ had SaaS, and 6\% had cloud ERP. Two years later, Panorama consulting [18] noted a disaggregated deployment landscape with $37 \%$ of the institutions having on-premises, 


\begin{tabular}{|c|c|c|c|}
\hline & Criteria & Characteristics & Examples \\
\hline Tier I & $\begin{array}{l}\text { Designed for } \\
\text { organizations } \\
\text { with more than } \\
\$ 750 \text { million in } \\
\text { annual revenue }\end{array}$ & $\begin{array}{l}\text { Designed for large } \\
\text { enterprises that have } \\
\text { complex processes within } \\
\text { their operations or } \\
\text { complexity around } \\
\text { consolidation and entity } \\
\text { management } \\
\text { Tier I applications } \\
\text { address multiple } \\
\text { industries and scalability }\end{array}$ & $\begin{array}{l}\text { - } \text { Infor LN } \\
\text { - } \text { Oracle Cloud Apps, } \\
\text { Infor M3 } \\
\text { - } \text { SAP S/4/HANA }\end{array}$ \\
\hline $\begin{array}{l}\text { Upper } \\
\text { Tier II }\end{array}$ & $\begin{array}{l}\text { Designed for } \\
\text { organizations } \\
\text { with } \$ 250 \text { million } \\
\text { to } \$ 750 \text { million in } \\
\text { annual revenue }\end{array}$ & $\begin{array}{l}\text { Small to medium size } \\
\text { organizations that serve } \\
\text { multiple industries and } \\
\text { have multiple business } \\
\text { units to manage }\end{array}$ & $\begin{array}{ll}\text { - } & \text { IFS } \\
\text { - } & \text { Microsoft Dynamics } \\
365 \text { for Finance and } \\
\text { Operations } \\
\text { - Sage Enterprise } \\
\text { Management }\end{array}$ \\
\hline $\begin{array}{l}\text { Lower } \\
\text { Tier II }\end{array}$ & $\begin{array}{l}\text { Designed for } \\
\text { organizations } \\
\text { with } \$ 10 \text { million } \\
\text { to } \$ 250 \text { million in } \\
\text { annual revenue }\end{array}$ & $\begin{array}{l}\text { Small to medium size } \\
\text { organizations that } \\
\text { typically serve one } \\
\text { industry and have a } \\
\text { single entity to manage }\end{array}$ & $\begin{array}{ll}\text { - } & \text { Infor CloudSuite } \\
\text { - } & \text { IQMS } \\
\text { - } & \text { Microsoft Dynamics } \\
& 365 \text { Business Central } \\
\text { - } & \text { Oracle NetSuite } \\
\text { - } & \text { Plex } \\
\text { - } & \text { SYSPRO }\end{array}$ \\
\hline Tier III & $\begin{array}{l}\text { Designed with } \\
\text { niche } \\
\text { functionality }\end{array}$ & $\begin{array}{ll}\text { - } & \text { Smaller organizations } \\
\text { - } & \text { Used to supplement a } \\
& \text { larger ERP system }\end{array}$ & $\begin{array}{ll}\text { - } & \text { Aptean } \\
\text { - } & \text { Sage ERP } 100 \\
\text { - } & \text { Sage ERP } 300\end{array}$ \\
\hline
\end{tabular}

Table 1. ERP market landscape tiers [18].

21\% having cloud ERP (multi-tenant), 20\% having SaaS, 14\% having cloud ERP (single tenant), $9 \%$ having hybrid cloud, and $2 \%$ having a different arrangement. This latter report shows a more granular analysis of the choice of deployment in ERP implementation. The next section provides an overview of some current and emerging trends. These are likely to disrupt the market, prompting responses that will spur change.

\section{Impact of Technology Trends on the ERP Market Landscape}

Gartner predicted that at the dawn of the $21^{\text {st }}$ century, ERP strategies would evolve into a new generation of enterprise systems [34]. As the ERP industry enters the 2020s, on-going disruptions in the digital world have also affected the ERP landscape. Kuula [35] describes digital disruptions as changes that occur when new digital technologies that are usually accompanied by new business models "affect the value proposition of existing goods and services." These include current digital disruptions, 


\begin{tabular}{|c|c|c|c|c|c|}
\hline $\begin{array}{l}\text { Vend- } \\
\text { or }\end{array}$ & $\begin{array}{c}\text { Flag- } \\
\text { ship } \\
\text { Product }\end{array}$ & Product Features & $\underset{t}{\text { Deploymen }}$ & $\begin{array}{c}\text { Scor } \\
\text { e }\end{array}$ & $\begin{array}{c}\text { Headquart } \\
\text { ers/ Global } \\
\text { Presence }\end{array}$ \\
\hline Epicor & $\begin{array}{l}\text { Epicor } \\
\text { ERP }\end{array}$ & $\begin{array}{l}\text { HCM tools, sophisticated MRP functionality, } \\
\text { and powerful financial tools like being a multi- } \\
\text { company, accounting, and consolidation and } \\
\text { allocation. }\end{array}$ & $\begin{array}{l}\text { On- } \\
\text { premises or } \\
\text { in the cloud }\end{array}$ & 4.2 & $\begin{array}{l}\text { Austin, } \\
\text { Texas } \\
\text { (USA); } 150 \\
\text { countries }\end{array}$ \\
\hline IFS & & $\begin{array}{l}\text { Engineer-to-order processes in asset } \\
\text { management features, along with HR, project } \\
\text { management, and multi-site planning. } \\
\text { - Designed for medium and large enterprises in } \\
\text { construction and engineering, aerospace, and } \\
\text { multimode manufacturing. }\end{array}$ & $\begin{array}{l}\text { Service } \\
\text { oriented } \\
\text { architecture }\end{array}$ & 4.1 & $\begin{array}{l}\text { Itasca, } \\
\text { Illinois } \\
\text { (USA); /50 } \\
\text { countries }\end{array}$ \\
\hline Infor & & $\begin{array}{l}\text { - A two tiered ERP approach that focuses both on } \\
\text { the front office business needs of an enterprise } \\
\text { and the back end operational requirements of } \\
\text { manufacturing. } \\
\text { - A shared services model for a wide range of } \\
\text { tasks, including accounts payable, accounts } \\
\text { receivable, HCM, SCM, and customer } \\
\text { management. } \\
\text { - Incorporates artificial intelligence and machine } \\
\text { learning functions, powerful analytics, and } \\
\text { reporting functions. } \\
\text { - Focuses on specific industry segments and } \\
\text { verticals such as manufacturing, consumer } \\
\text { goods, services, public sector, and energy. }\end{array}$ & $\begin{array}{l}\text { Cloud based } \\
\text { platform }\end{array}$ & 4.3 & $\begin{array}{l}\text { New York, } \\
\text { NY (USA) }\end{array}$ \\
\hline $\begin{array}{l}\text { Micro } \\
\text { soft }\end{array}$ & $\begin{array}{l}\text { Microso } \\
\mathrm{ft} \\
\text { Dynami } \\
\text { cs } 365\end{array}$ & $\begin{array}{l}\text { - Mainly for finance and operations incorporated } \\
\text { CRM features. } \\
\text { - Strengths in business intelligence (BI) and real- } \\
\text { time multi-dimensional analytics that can be } \\
\text { used in demand forecasting and product change } \\
\text { management tools with granular tracking of } \\
\text { products and serial numbers. }\end{array}$ & $\begin{array}{l}\text { On- } \\
\text { premises or } \\
\text { SaaS }\end{array}$ & 4.5 & $\begin{array}{l}\text { Redmond, } \\
\text { Washington } \\
\text { (USA), } 118 \\
\text { countries }\end{array}$ \\
\hline Oracle & $\begin{array}{l}\text { Oracle } \\
\text { ERP } \\
\text { NetSuit } \\
\text { e }\end{array}$ & $\begin{array}{l}\text { - Considered a top tier provider of ERP solutions } \\
\text { with both flagship products, delivering powerful } \\
\text { embedded reporting and analytics tools and } \\
\text { capabilities to manage assets across their } \\
\text { lifecycle. } \\
\text { - Oracle ERP leads in breadth and depth of } \\
\text { features and functionality. } \\
\text { - NetSuite focused on financial services and } \\
\text { financial management with integration with } \\
\text { Salesforce and other business software } \\
\text { platforms. }\end{array}$ & SaaS & 4.8 & $\begin{array}{l}\text { Redwood } \\
\text { City, } \\
\text { California } \\
\text { (USA) }\end{array}$ \\
\hline QAD & & $\begin{array}{l}\text { Integrated platform that connects various tasks, } \\
\text { such as engineering, customer service, supply } \\
\text { chain, and finance, without various add-ons and } \\
\text { third party additions. }\end{array}$ & $\begin{array}{l}\text { Cloud based } \\
\text { framework } \\
\text { to create an } \\
\text { Anything- } \\
\text { as-a-Service } \\
\text { (XaaS) } \\
\text { business } \\
\text { environment }\end{array}$ & 4.3 & $\begin{array}{l}\text { Santa } \\
\text { Barbara, } \\
\text { California } \\
\text { (USA) }\end{array}$ \\
\hline
\end{tabular}




\begin{tabular}{|c|c|c|c|c|c|}
\hline $\begin{array}{l}\text { Vend- } \\
\text { or }\end{array}$ & $\begin{array}{l}\text { Flag- } \\
\text { ship } \\
\text { Product }\end{array}$ & Product Features & $\underset{t}{\text { Deploymen }}$ & $\begin{array}{c}\text { Scor } \\
\text { e }\end{array}$ & $\begin{array}{l}\text { Headquart } \\
\text { ers/ Global } \\
\text { Presence }\end{array}$ \\
\hline $\begin{array}{l}\text { Rootst } \\
\text { ock }\end{array}$ & & $\begin{array}{l}\text { - Integrated approach to sales, sales order } \\
\text { processing, engineering, supply chain, } \\
\text { production, inventory, logistics, and financials. } \\
\text { Works with other leading business and financial } \\
\text { applications using APIs (e.g., Salesforce). }\end{array}$ & Cloud based & 4.3 & $\begin{array}{l}\text { Rootstock, } \\
\text { California } \\
\text { (USA) }\end{array}$ \\
\hline Sage & $\begin{array}{l}\text { Sage } \\
300 \\
\text { ERP } \\
\text { Sage } \\
100 \mathrm{c} \\
\\
\text { Sage } \\
\text { Intacct }\end{array}$ & $\begin{array}{l}\text { - Offers payroll and HR products and tools with } \\
\text { integration tools to products like Salesforce. } \\
\text { - Focuses on construction, manufacturing, } \\
\text { chemicals, food and beverage, professional } \\
\text { services, and non-profits. } \\
\text { - Three products with a different emphasis: } \\
\text { - Sage } 300 \text { ERP: a business management platform } \\
\text { for large global enterprises; } \\
\text { - Sage 100c: small and medium businesses; } \\
\text { - Sage Intacct: delivers financial tools. }\end{array}$ & Cloud based & 4.4 & $\begin{array}{l}\text { Atlanta, } \\
\text { Georgia } \\
\text { (USA) }\end{array}$ \\
\hline SAP & $\begin{array}{l}\text { SAP } \\
\text { ERP } \\
\text { SAP } \\
\text { S/4HA } \\
\text { NA } \\
\text { SAP } \\
\text { Busines } \\
\text { s One }\end{array}$ & $\begin{array}{l}\text { - Pioneered the ERP space and continues to be a } \\
\text { top vendor. } \\
\text { - Has more than three dozen products and } \\
\text { solutions for treasury and financial risk } \\
\text { management tools, HR components, } \\
\text { procurement, logistics, and SCM capabilities. } \\
\text { Offers solutions for predictive analytics, data } \\
\text { management, machine learning, Internet of } \\
\text { things, cyber security, and governance risk and } \\
\text { compliance. }\end{array}$ & $\begin{array}{l}\text { On- } \\
\text { premises } \\
\text { and cloud } \\
\text { solutions }\end{array}$ & 4.7 & $\begin{array}{l}\text { Waldorf } \\
\text { (Germany) }\end{array}$ \\
\hline $\begin{array}{l}\text { SYSP } \\
\text { RO }\end{array}$ & & $\begin{array}{l}\text { - Offers a comprehensive set of tools and features } \\
\text { aimed at managing manufacturing with an end } \\
\text { to end approach focused on production, } \\
\text { distribution, and inventory management. } \\
\text { Offers industry specific software for automotive, } \\
\text { electronics, food and beverage, industrial } \\
\text { machinery and equipment, fabricated metals, } \\
\text { packaging, plastics, and rubber, etc. }\end{array}$ & & 4.5 & $\begin{array}{l}\text { Costa Mesa, } \\
\text { California } \\
\text { (USA) }\end{array}$ \\
\hline
\end{tabular}

Table 2. ERP market landscape [2].

like cloud computing, process robotics, and visualization, as well as emerging digital disruptions, such as advanced analytics, blockchain, and cognitive computing [36]. For instance, visualization helps in presenting data generated within ERPs in ways that ensure they can be easily leveraged in decision-making. This may include external tools, such as Tableau Desktop or Microsoft's Power BI, which give users new options for data processing and consumption [15]. This section will discuss several technological trends, namely, the Fourth Industrial Revolution, cloud computing, artificial intelligence, and blockchain technology. 


\subsection{Fourth Industrial Revolution}

In order to understand the Fourth Industrial Revolution, also known as Industry 4.0 or $4 I R$, one has to understand the preceding industrial revolutions. The First Industrial Revolution lasted between mid- $18^{\text {th }}$ century to mid- $19^{\text {th }}$ century and was marked by a transition in an agrarian society from hand production methods to machines through the use of steam and water power, the distinguishing principle being machine productivity [37], [38]. The Second Industrial Revolution lasted between the mid-19 ${ }^{\text {th }}$ century to the early $20^{\text {th }}$ century and was marked by the extensive installation of railroad and telegraph networks, the distinguishing principle being scientific management [37], [38]. The Third Industrial Revolution occurred from the mid-20 $0^{\text {th }}$ century until the early $21^{\text {st }}$ century and characterised by the development and ubiquity of digital technologies and decentralized networks. ERPs were among those technologies that emerged during the Third Industrial Revolution. The phrase Fourth Industrial Revolution is attributed to the Klaus Schwab, who introduced it in 2015 [39], [40]. This fourth phase has been characterised by automation of traditional manufacturing and industrial practices as well as the increasing use of smart technology, including large scale machine to machine communication and the Internet of Things that improve communication, self-monitoring, and the product of smart machines [41].

While the 4IR is increasingly being adopted by governments in their technology development strategies, some researchers have also noted that ERPs will form a key part of the 4IR agenda. For instance, in manufacturing processes, ERPs dominated other types of information systems [42] while in the health sector, ERPs were increasingly being used to integrated hospital management operations [43], [44].

\subsection{Artificial Intelligence}

Artificial intelligence (AI) is a discipline that has existed since the $1950 \mathrm{~s}$ and is described as intelligence demonstrated by machines in contrast to natural intelligence displayed by humans or animals [37], [45]. It has most recently received heightened interest with the technological developments seen in cloud computing and the platform created in the 4IR. An example of increased interest is seen with the proliferation of an increasing amount of digital content that is difficult to search. AI is seen as a means of enhancing search mechanisms [46]. Girasa [37] argues that there are three categories of artificial intelligence: artificial narrow intelligence (ANI), artificial general intelligence (AGI), and artificial super intelligence (ASI). These are seen as progressive, with ANI being limited to performing singular tasks such as making sales predictions or autonomously driving vehicles. AGI is considered human level, in which machines are able to imitate human reasoning. ASI is considered futuristic, in which machines will surpass human creativity, social skills, and ability to make complex decisions [37].

Basl and Marketa [47] conducted research amongst ERP system supplies and found that while most indicated that artificial intelligence was at the core of their systems, less than a quarter were actively expanding their ERP systems with artificial 
intelligence. In their research, most responding institutions used AI in predictive inventory management with two thirds of those in decision support as well as data analysis and processing [47]. Other common AI applications include conversational AI platforms that include virtual assistants and chatbots, as well as predictive analytics models [48]. This demonstrates that most ERPs were involved in ANI and not AGI or ASI.

\subsection{Cloud Computing}

Mell and Grance [49] define cloud computing as a model "for enabling ubiquitous, convenient, on-demand network access to a shared pool of configurable computing resources (e.g., networks, servers, storage, applications, and services) that can be rapidly provisioned and released with minimal management effort or service provider interaction." At the most fundamental level, there are three cloud computing service models [49]:

1. Software as a Service (SaaS): Delivers software applications through a thin client interface so that users do not manage or control underlying infrastructure.

2. Platform as a Service (PaaS): Delivers middleware used by developers to build and configure SaaS applications.

3. Infrastructure as a Service (IaaS): Delivers computing power such as storage, network, and provision processing, used to deploy and run software.

The ERP market has been undergoing a generational technology shift driven by the advent of cloud computing [3]. Cloud based ERPs emerged by the mid-2000s due to two perceived benefits: using closely coupled systems and moving away from managing on-premises ERPs [50].

\subsubsection{Close Coupling VS. Cloud Based ERPS}

Martinez [51] argued that ERP vendors built traditional ERP tools to be comprehensive, meaning they were full suites that combined BI, CRM, general ledger accounting, and HR applications that are tied directly to preconceived, specific business use cases and devices. In contrast, cloud-based ERP vendors built apps that are broken into separate modules that can seamlessly connect. This means that if an institution needs BI and CRM apps (but do not need HR management and point of sale [POS]) apps, it is a matter of toggling apps on or off [51]. In this way, cloud delivered apps allow customized and feature relevant modules, enabling institutions to rapidly respond to internal integration and workflow needs [52].

\subsubsection{On-Premise Systems Vs. Cloud Based ERPs}

Most ERP vendors build everything on the same digital architecture. This means that one is getting the same user interface (UI) across every module-from CRM to ecommerce to general ledger. This also means that one is only using one security protocol to monitor and protect the data within this architecture. The more apps that 
one combines, the more security adjustments need to be made. In addition, at the core, most work uses a general ledger core. Therefore, combining ERPs from different vendors means duplicating the core [51].

Initially, traditional ERPs were built as on-premises apps. Like all enterprise systems, IT professionals in institutions must update them regularly to fix bugs, tighten security, extend current functionalities and modules, convene market and legal regulations, update processes, and meet the evolving organizations [50]. However, these processes, when conducted on-premises, have been cumbersome considering the granular nature of each activity and the need to monitor the technical change processes.

In contrast, cloud implementations allow information technology professionals to update apps when new features and security patches become available [51], [53]. However, this also means that cloud ERP users are no longer in control of the updates and upgrades and maintenance decisions. As Bjelland and Haddara [50] stated, "maintenance and update decisions and efforts are solely triggered and conducted on chosen dates by ERP vendors."

\subsection{Blockchain Technology}

Blockchain technology, which was first implemented in 2009, was the underlying platform designed to solve a problem with the cryptocurrency, Bitcoin, to transfer digital value without relying on a trusted third party [54]. The terminology is still confusing because the technology is evolving. For regulators in the financial world, the rapidly shifting and contested vocabulary is difficult to understand and govern [55]. Nonetheless, Lemieux, Hofman, Batista, and Joo [56] described this "technology of trust" as a type of distributed ledger comprised of confirmed and validated blocks cryptographically chained together.

Researchers see blockchain technology as a solution to a global crisis of trust. Therefore, some advocates argue that the technology's unique capabilities serve to negate the need for trust, calling it a trust-less technology [57], [58]. However, Lemieux, Hofman, Batista, and Joo [56] argued that in practice, blockchain does not obviate the need for trust. Instead, it replaces more traditional, and often inefficient or flawed, means of obtaining information and establishing trust, such as traditional legal contracts, with a new, more efficient source of information. The substitution does not negate the need for trust. It is an evolution based on incentive mechanisms, record creation, recordkeeping, and decentralization [56]. Blockchain has three interacting trust layers in technology (Figure 1).

According to Lemieux, Hofman, Batista, and Joo [56], the social layer "is where social actors interact with one another and determine how much information they need, and in what form (e.g., by social convention, how much from the blockchain system and how much from other sources external to the system) in order to be able to trust and take action on the basis of trust." The data or record layer "supplies the information that social actors have decided they need to obtain from the blockchain system to give them confidence to act" [56]. Finally, the technical layer "technical 
means by which social actors interact and create, store, and obtain information about those interactions as tamper resistant and non-reputable proof of facts about acts" [56].

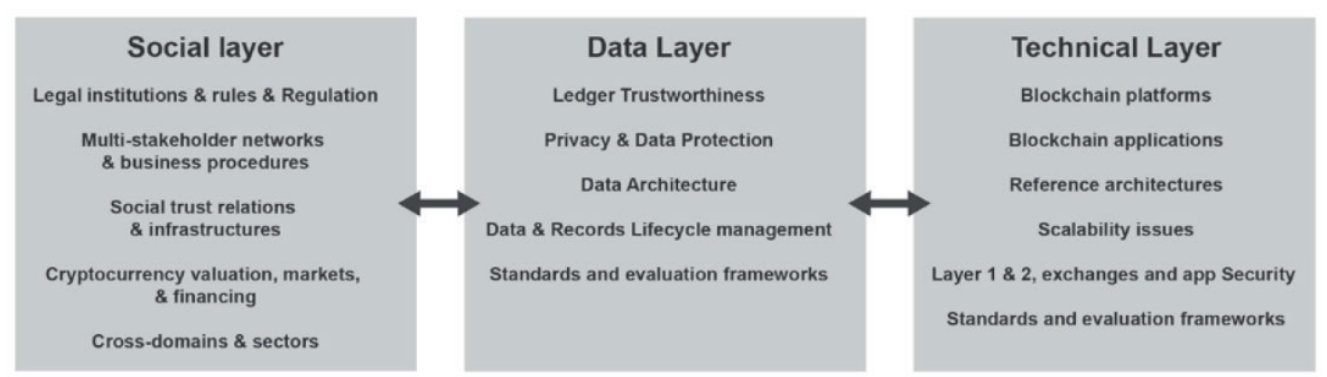

Figure 1. Three layer trust model for blockchain technology [56].

This final layer blockchain is a data structure that is technically implemented in a decentralized peer to peer network. It offers the possibility to define and hold both data and functions in single blocks [59].

Since the mid-2010s, there have been various efforts to develop enterprise blockchain that will eventually roll out blockchain as infrastructure [60]. According to George, Peterson, Yaros, Beam, Dibbell, and Moore [54], many current supply chain processes rely on non-standardised paper and digital records held among various parties. This often results in difficulties pinpointing problems in the chain. With blockchain, an ERP system can provide an integrated platform across partners and stakeholders, providing data that cannot be manipulated (i.e., true record) and an audit trail for transactions that happen within the extended ERP network [54], [61]. For this reason, several ERP vendors are developing blockchain platforms and protocols, such as SAP Cloud Platform Blockchain and Oracle Blockchain [60]. Pelz-Sharpe [60] expects that ERP vendors, such as SAP, Oracle, and Microsoft, will eventually be major infrastructure vendors for blockchain as a service (BaaS).

In general terms, the ability of ERPs to provide network solutions is typically limited to implementation within the boundaries of an enterprise [62]. Therefore, only a truly decentralized blockchain implementation must operate outside this limitation. For this reason, there are efforts to integrate information technology landscapes and disparate ERP systems to ecosystems of blockchains. For instance, Schmidt et al. [59] used a unified framework for blockchain based business integration, Unibright Connector, to connect separate ERP systems, as illustrated in Figure 2.

Figure 2 illustrates the ability to encapsulate communication technologies of two different ERPs (SAP and Oracle) with different blockchain platform channels using an Unibright Connector. It is also possible to use blockchain to orchestrate multiple workflows in both public and private blockchains for products such as smart contracts. Additionally, this is possible in integrated scenarios, including an ERP system, as illustrated in Figure 3 [59].

Figure 3 illustrates how an institute with access to a public blockchain environment tries to institute a smart contract that is connected to the institution's ERP 
system. This will undergo internal processing within the ERP; then it is delivered to a private blockchain for completion of the second and final workflow process [59].

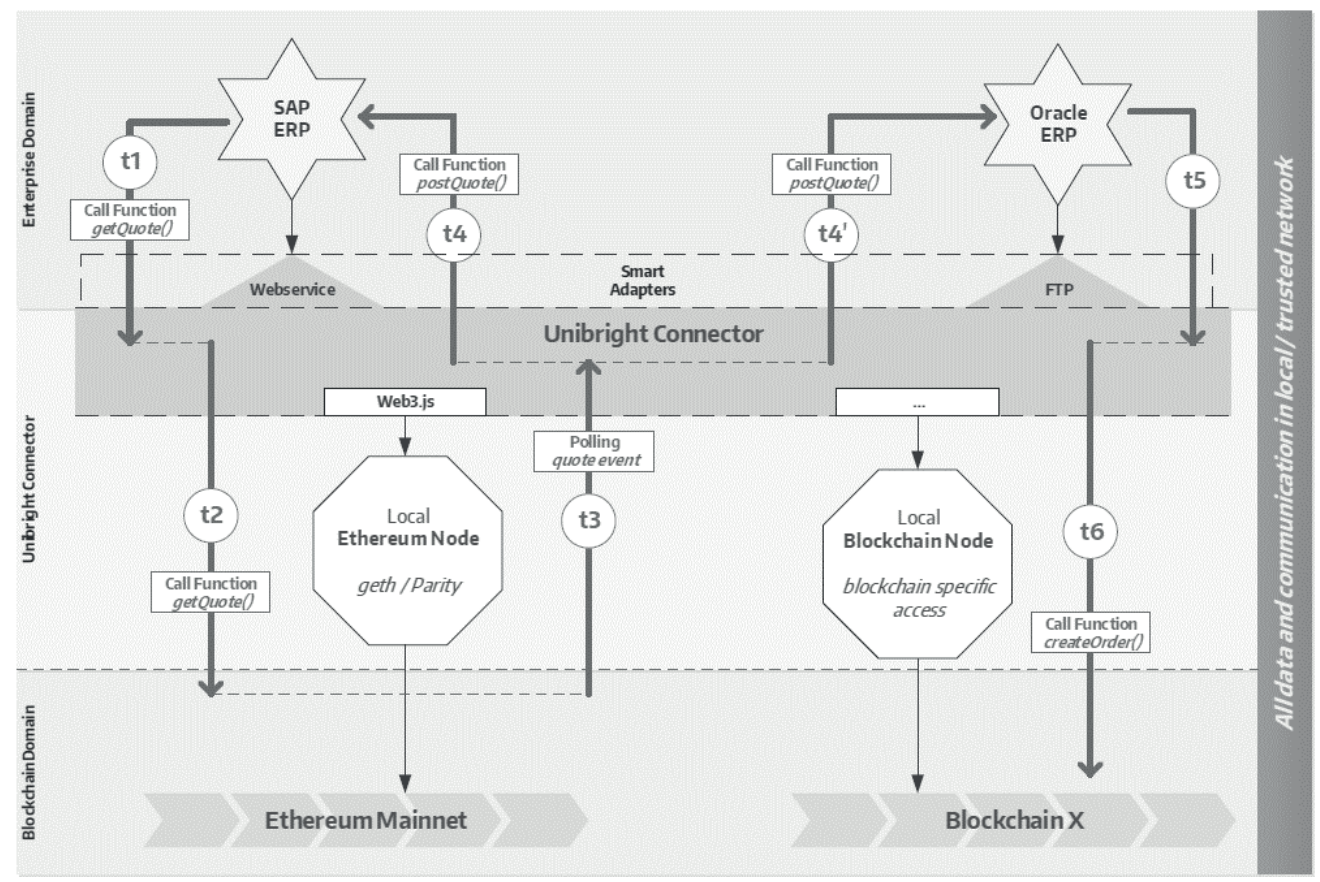

Figure 2. Unibright Connector architecture [59].

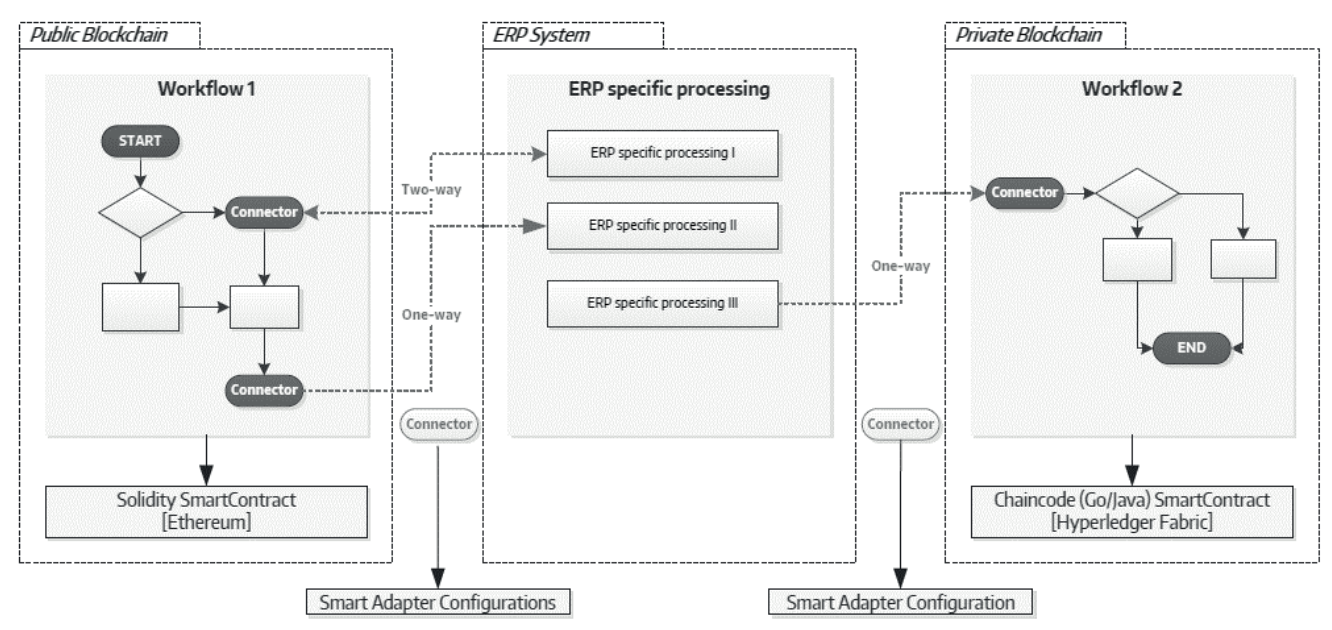

Figure 3. Orchestrating workflows [59]. 


\section{Discussion and Conclusion}

Of the four trends discussed in the paper, cloud computing is the one most frequently reported because it is seen as a drastic gateway to modernization compared to previous ERP solutions [47]. Nonetheless, 4IR platforms, particularly the opportunities to connect ERPs to smart devices, open up huge opportunities to harness real-time data and support decision making within institutions [45], [47].

Figure 4 illustrates how ERP innovations are possible with a digital core and cloud $\mathrm{PaaS}$ from vendors that support varied technologies [36]. On the outer core of the illustration are various technologies discussed in this article. Starting clockwise from the top, these technologies are networking platforms, machine learning, blockchain, android devices, SAP Leonardo, wearable devices, technology in scientific research, mobile devices, industrial robotics, artificial intelligence, and Apple devices [63] [67].
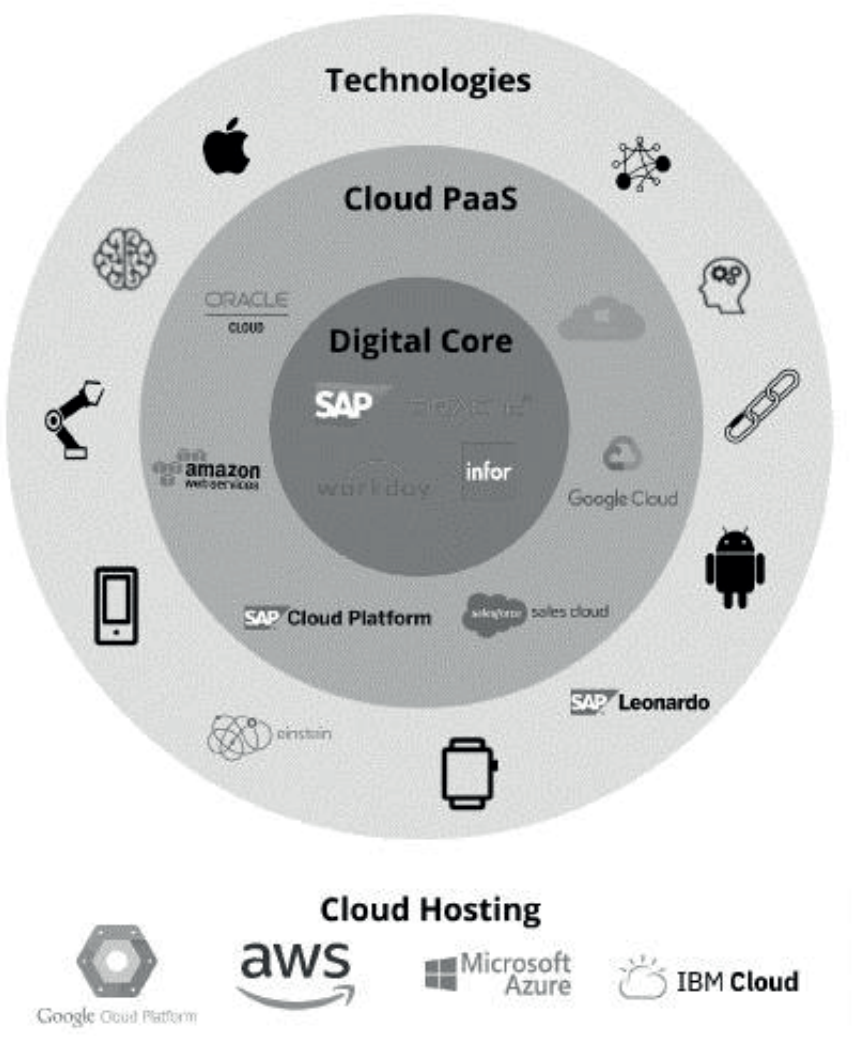

Figure 4. ERP innovation [36].

As Figure 4 demonstrates, cloud computing makes it easy for institutions to use ERPs on mobile devices [68].

In 2019, Gartner stated that ERP systems were one of the largest categories of enterprise software spending and added that by $2022,30 \%$ of large enterprises will have moved to a platform and product-centric approach with standardized ERP 
capabilities at the platform core [69]. This continued growth partly illustrates why ERP systems remain vital enabling technologies within institutions. This article has provided a brief overview of the ERP market landscape. While there have been many ERP vendors since its start in the 1940s, some have disappeared through mergers/acquisitions, while others have emerged [30].

Since the early 2000s, new digital innovations have impacted the ERP landscape, including advanced analytics, cognitive computing, and visualization [36]. The digital revolution has been characterised by the convergence of technologies that improve the efficiency and effectiveness of business processes [70]. This article examined how four trends, 4IR, AI, cloud computing, and blockchain technology, have impacted and continue to impact the trajectory of developments within the ERP market. While the discussion was limited to these technologies, there are many other trends, including open source ERP models as well as machine learning [71], [72]. These discussions are necessary for the current ecosystems within ERP systems because it is easy to get lost in the complexity of the rapidly evolving market landscape. The impact of external influences from such technologies requires working outside an ERP's ecosystem. Therefore, this fundamentally challenges how future ERPs will be built and used [73]. All these considerations are critical for information management professionals in their quest to fulfil their institutional mandates, particularly since discussions on ERPs systems and current developments may not be included in formal education and training [74],[75].

\section{Acknowledgements}

Research leading to this article was funded by South Africa's National Research Foundation Grant Number 114856. The views expressed herein are those of the author and should neither be attributed to their current employer nor to any of their previous employers.

\section{References}

[1] P. Parmar, "Managing electronic supply chains," Managing Operations Throughout Global Supply Chains, J. C. Essila, Ed. Hershey, PA: IGI Global, 2019, pp. 181-197.

[2] S. Greengard, Top 10 Enterprise Resource Planning Software Providers. City, 2019.

[3] J. E. Van Decker, R. P. Anderson, and G. Leiter, "Magic Quadrant for Cloud Core Financial Management Suites for midsize, large and global enterprises," Gartner [Online]. Available:

https://b2bsalescafe.files.wordpress.com/2019/09/gartner-magic-quadrantfor-cloud-core-financial-management-suites-for-midsize-large-and-globalenterprises-may-2019.pdf [Accessed: Aug. 22, 2020]. 
[4] S. Katuu, "Enterprise Architecture-A Value Proposition for Records Professionals," In 2019 IEEE International Conference on Big Data, Los Angeles, CA, C. Baru, J. Huan, L. Khan, X. Hu, R. Ak, Y. Tian, R. Barga, C. Zaniolo, K. Lee, and Y. F. Ye, Eds. IEEE, 2019, pp. 3116-3125.

[5] R. Marciano, V. Lemieux, M. Hedges, Y. Tomiura, S. Katuu, J. Greenberg, W. Underwood, K. Fenlon, A. Kriesberg, M. Kendig, G. Jansen, P. Piety, D. Weintrop, and M. Kurtz, "Establishing an international computational network for librarians and archivists," University of Maryland, College Park [Online]. Available:

https://www.ideals.illinois.edu/bitstream/handle/2142/103139/Marciano_et _al_BlueSky2.pdf?sequence=4\&isAllowed=y, [Accessed: Aug. 22, 2020].

[6] M. Ali and L. Miller, "ERP system implementation in large enterprises: A systematic literature review," Journal of Enterprise Information Management, vol. 30, no. 4, pp. 666-692, 2017.

[7] M. A. A. Elmonem, E. S. Nasr, and M. H, Geith, "Benefits and challenges of cloud ERP systems: A systematic literature review," Future Computing and Informatics Journal, vol. 1, no. 1-2, pp. 1-9, 2016.

[8] V. M. Khaparde, "Barriers of ERP while implementing ERP: A Literature Review," Journal of Mechanical and Civil Engineering, vol. 3, no. 6, pp. 49-91, 2012.

[9] Y. Moon, "Enterprise resource planning (ERP): A review of the literature," International Journal Management and Enterprise Development, vol. 4, no. 3, pp. 235-264, 2007.

[10] S. Ranjan, V. K. Jha, and P. Pal, "Literature review on ERP implementation challenges," International Journal of Business Information Systems, vol. 21, no. 3, pp. 388-402, 2016.

[11] C. Dahlén and J. Elfsson, An Analysis of the Current and Future ERP Market. Sweden: The Royal Institute of Technology, 1999.

[12] B. Erkut, "The emergence of the ERP software market between product innovation and market shaping," Journal of Open Innovation: Technology, Market, and Complexity, vol. 4, no. 3, pp. 1-23, 2018.

[13] S. Katuu, "Conducting research: Graduate level literature reviews," University of South Africa, Pretoria, South Africa [Online]. Available: https://www.researchgate.net/publication/343725059_Conducting_research _-_graduate_level_literature_reviews/ [Accessed: Aug. 22, 2020]. 
[14] J. T. F. Callejas and C. Terzi "Review of enterprise resource planning (ERP) systems in United Nations organizations: JIU/REP/2012/8," Joint Inspection Unit: United Nations, Geneva [Online]. Available: https://www.unjiu.org/sites/www.unjiu.org/files/jiu_document_files/produ cts/en/reports-notes/JIU\%20Products/JIU_REP_2010_6_English.pdf [Accessed: Aug. 22, 2020].

[15] O. Rist and J. Martinez, "5 enterprise resource planning (ERP) trends to watch in 2019" [Online]. Available:

https://www.pcmag.com/article/351807/5-enterprise-resource-planningerp-trends-to-watch-in-2019 [Accessed: Aug. 22, 2020].

[16] E. Nazemi, M. J. Tarokh, and G. R. Djavanshir, "ERP: A literature survey," International Journal of Advanced Manufacturing Technology, vol. 61, no. 9-12, pp. 999-1018, 2012.

[17] S. Katuu, "Enterprise resource planning: Past, present and future," New Review of Information Networking, vol. 25, no. 1, pp. 37-46, 2020.

[18] Panorama Consulting "2019 ERP report: People, process, technology" [Online]. Available: https://cdn2.hubspot.net/hubfs/4439340/2019-ERPReport-3.pdf [Accessed: Aug. 22, 2020].

[19] M. Guay, "Postmodern ERP strategies and considerations for midmarket IT leaders," Gartner [Online]. Available: http://proyectos.andi.com.co/camarabpo/Webinar\%202016/Postmodern $\% 2$ 0ERP\%20strategies $\% 20$ and $\% 20$ considerations $\% 20$ for $\% 20$ midmarket $\% 20$ I T\%201eaders-\%20Gartner.pdf [Accessed: Aug. 22, 2020].

[20] Gartner, “Gartner Glossary: Postmodern ERP” [Online]. Available: https://www.gartner.com/en/information-technology/glossary/postmodernerp [Accessed: Aug. 22, 2020].

[21] H. L. Meghana, A. O. Mathew, and L. L. R. Rodrigues, "Prioritizing the factors affecting cloud ERP adoption: An analytic hierarchy process approach," International Journal of Emerging Markets, vol. 13, no. 6, pp. 1559-1577, 2018.

[22] B. Molnár, "The country-specific organizational and information architecture of ERP systems at Globalised Enterprises," Business Systems Research, vol. 2, no. 2, pp. 39-50, 2011.

[23] Y. Xie, C. J. Allen, and M. Ali, “An integrated decision support system for ERP implementation in small and medium sized enterprises," Journal of Enterprise Information Management, vol. 27, no. 4, pp. 358-384, 2014.

[24] C. Møller, "ERP II: A conceptual framework for next-generation enterprise systems?" Journal of Enterprise Information Management, vol. 18, no. 4, pp. 483-497, 2005. 
[25] E. Chan and A. Mills, "Implementation of enterprise resource planning (ERP) software in a major construction contracting organization in Hong Kong," International Journal of Managing Projects in Business, vol. 4, no. 1, pp. 168-178, 2011.

[26] N. A. Panayiotou, S. P. Gayialis, N. P. Evangelopoulos, and P. K. Katimertzoglou, "A business process modeling-enabled requirements engineering framework for ERP implementation," Business Process Management Journal, vol. 21, no. 3, pp. 628-664, 2015.

[27] G. Capaldo and P. Rippa, "A planned-oriented approach for EPR implementation strategy selection," Journal of Enterprise Information Management, vol. 22, no. 6, pp. 642-659, 2009.

[28] E. Yontar, "A comparative study to evaluate of SAP and LOGO ERP software's for SMEs and big businesses," Turkish Journal of Engineering, vol. 3, no. 1, pp. 1-8, 2019.

[29] W. She and B. Thuraisingham, "Security for enterprise resource planning systems," Information Systems Security, vol. 16, no. 3, pp. 152-163, 2007.

[30] M. A. Rashid, L. Hossain, and J. D. Patrick, "The evolution of ERP systems: A historical perspective," Enterprise Resource Planning: Solutions and Management, IGI Global, 2002, pp. 35-50.

[31] C. Jones, The Technical and Social History of Software Engineering. Upper Saddle River, NJ: Addison-Wesley, 2013.

[32] Y. Zare Mehrjerdi, "Enterprise resource planning: Risk and benefit analysis," Business Strategy Series, vol. 11, no. 5, pp. 308-324, 2010.

[33] Panorama Consulting, "2017 Report on ERP systems and enterprise software" [Online]. Available: https://www.panorama-consulting.com/wpcontent/uploads/2017/07/2017-ERP-Report.pdf [Accessed: Aug. 22, 2020].

[34] N. Wood, B. Bond, Y. Genovese, B. Zrimsek, N. Rayner, and D. Miklovic, "ERP is dead-Long live ERP II," New York: Gartner Group [Online]. Available: https://www.gartner.com/en/documents/314701/erp-is-deadlong-live-erp-ii [Accessed: Aug. 22, 2020].

[35] S. Kuula and H. Haapasalo, "Continuous and co-creative business model creation," in Service Business Model Innovation in Healthcare and Hospital Management, M. A. Pfannstiel and C. Rasche, Eds. Springer, 2017, pp. 249-268.

[36] M. Stallard, “ERP and enabling technologies,” Deloitte [Online]. Available:

https://www2.deloitte.com/content/dam/Deloitte/uk/Documents/publicsector/deloitte-uk-matt-stallard-erp-and-enabling-technologies.pdf [Accessed: Aug. 22, 2020]. 
[37] R. Girasa, Artificial Intelligence as a Disruptive Technology. Pleasantville, NY: Palgrave Macmillan, 2020.

[38] Ž. Stojkić, I. Veža, and I. Bošnjak, “Concept of information system implementation (CRM and ERP) within Industry 4.0," In 26th DAAAM International Symposium on Intelligent Manufacturing and Automation, Vienna, Austria, B. Katalinic, Ed. DAAAM International, 2016, 09120919.

[39] K. Schwab, "The Fourth Industrial Revolution: What it means and how to respond," Foreign Affairs [Online]. Available:

https://www.foreignaffairs.com/articles/2015-12-12/fourth-industrialrevolution [Accessed: Aug. 22, 2020].

[40] M. Xu, J. M., David, and S. H. Kim, "The Fourth Industrial Revolution: opportunities and challenges. International Journal of Financial Research, 9, 2 (2018), 90-95.

[41] S. P. da Costa and N. Costa, "Industrial occupational safety: Industry 4.0 upcoming challenges," Safety and Security Issues in Technical Infrastructures, D. Rehak, A. Bernatik, Z. Dvorak, and M. Hromada, Eds. IGI Global, 2020, pp. 152-172.

[42] Y. Liao, L. F. P. Ramos, M. Saturno, F. Deschamps, E. d. F. R. Loures, and A. L. Szejka, "The role of interoperability in the Fourth Industrial Revolution era," IFAC-PapersOnLine, vol. 50, no. 1, pp. 12434-12439, 2017.

[43] S. Katuu, “Transforming South Africa's health sector: The eHealth strategy, the implementation of electronic document and records management systems (EDRMS) and the utility of maturity models," Journal of Science and Technology Policy Management, vol. 7, no. 3, pp. 330-345, 2016.

[44] M. Lee, Y. Yoon, G. H. Ryu, H. S. Bok, K. Yoon, S. Park, and K.-S. Lee, "Innovative distribution priorities for the medical devices industry in the Fourth Industrial Revolution," International Neurourology Journal, vol. 22, Supplement 2, pp. 83-90, 2018.

[45] M. Helmold, Lean Management and Kaizen: Fundamentals From Cases And Examples In Operations And Supply Chain Management. Berlin, Germany: Springer, 2020.

[46] A. Pelz-Sharpe, “Oracle Intelligent Track and Trace," Deep Analysis [Online]. Available: https://www.oracle.com/a/ocom/docs/blockchain/deep-analysis-oracleintelligent-track-and-trace-2020.pdf [Accessed: Aug. 22, 2020]. 
[47] J. Basl and M. Novakova, "Analysis of selected ERP 4.0 features and proposal of an ERP 4.0 maturity model," In Research and Practical Issues of Enterprise Information Systems: 13th IFIP WG 8.9 International Conference, CONFENIS 2019, Prague, Czech Republic, December 16-17, P. Doucek, J. Basl, A. M. Tjoa, M. Raffai, A. Pavlicek, and K. Detter, Eds. Springer Nature, 2019, pp. 3-11.

[48] A. Krishnamoorthy, "How to leverage AI technology for a winning ERP strategy," Acumatica [Online]. Available:

https://www.acumatica.com/blog/how-leverage-ai-technology-forwinning-erp-strategy-gartner-research-note/, [Accessed: Aug. 22, 2020].

[49] P. Mell and T. Grance, The NIST Definition of Cloud Computing. Gaithersburg, MD: National Institute of Standards and Technology, 2011.

[50] E. Bjelland and M. Haddara, "Evolution of ERP systems in the cloud: A study on system updates," Systems, vol. 6, no. 22, pp. 1-26, 2018.

[51] J. Martinez, "Is enterprise resource planning (ERP) software dead?" [Online]. Available: https://www.pcmag.com/article/353591/is-enterpriseresource-planning-erp-software-dead [22nd August, 2020].

[52] C. Saran, "Can cloud-based ERP buy you business agility?" [Online]. Available: https://www.computerweekly.com/feature/Can-cloud-basedERP-buy-you-business-agility [Accessed: Aug. 22, 2020].

[53] B. M. Shabou, M. Guercio, S. Katuu, E. Lomas, and A. Grazhenskayas, "Strategies, methods and tools enabling records governance in a cloud environment," in Trusting Records in the Cloud: The creation, Management, and Preservation of Trustworthy Digital Content, L. Duranti and C. Rogers, Eds. London, UK: Facet Publishing, 2019, pp. 97-116.

[54] R. P. George, B. L. Peterson, O. Yaros, D. L. Beam, J. M. Dibbell, and R. C. Moore, "Blockchain for business," Journal of Investment Compliance, vol. 20, no. 1, pp. 17-21, 2019.

[55] A. Walch, "The path of the blockchain lexicon (and the law)," Review of Banking and Financial Law, vol. 36, pp. 713-765, 2016.

[56] V. Lemieux, D. Hofman, D. Batista, and A. Joo, "Blockchain technology and recordkeeping," ARMA International Educational Foundation [Online]. Available: https://www.researchgate.net/profile/Victoria_Lemieux/publication/33365 9272_Blockchain_Technology_Recordkeeping/links/5cfadaaf299bf13a384 5866e/Blockchain-Technology-Recordkeeping.pdf [Accessed: Aug. 22, 2020]. 
[57] M. Klems, J. Eberhardt, S. Tai, S. Härtlein, S. Buchholz, and A. Tidjani, "Trustless intermediation in blockchain-based decentralized service marketplaces," in International Conference on Service-Oriented Computing, ICSOC 2017, M. Maximilien, A. Vallecillo, J. Wang, and M. Oriol, Eds. Cham, Switzerland: Springer, 2017, pp. 731-739.

[58] Q. Xia, E. B. Sifah, K. O. Asamoah, J. Gao, X. Du, and M. Guizani, "MeDShare: Trust-less medical data sharing among cloud service providers via blockchain," IEEE Access, vol. 5, pp. 14757-14767, 2017.

[59] S. Schmidt, M. Jung, T. Schmidt, I. Sterzinge, G. Schmidt, M. Gomm, K. Tschirschke, T. Reisinger, F. Schlarb, D. Benkenstein, and B. Emig, "Unibright: The unified framework for blockchain based business integration" [Online]. Available:

https://neironix.io/documents/whitepaper/3d4c0f5db2e4c6ffff57a281b26af e08.pdf [Accessed: Aug. 22, 2020].

[60] A. Pelz-Sharpe, "Enterprise blockchain market forecast and scenarios 2019-2024," Deep Analysis [Online]. Available: https://www.deepanalysis.net/wp-content/uploads/2019/08/DA-190812-Ent-Blockchainforecast.pdf [Accessed: Aug. 22, 2020].

[61] A. Banerjee, "Blockchain technology: Supply chain insights from ERP," Advances in Computers, vol. 111. P. Raj and G. C. Deka, Eds. Elsevier, pp. 69-98, 2018.

[62] R. Cole, M. Stevenson, and J. Aitken, "Blockchain technology: Implications for operations and supply chain management," Supply Chain Management: An International Journal, vol. 24, no. 4, pp. 469-483, 2019.

[63] Getty Images, "Artificial intelligence” [Online]. Available: https://www.gettyimages.com/detail/illustration/simple-set-of-artificialintelligence-royalty-free-illustration/1185273300 [Accessed: Aug. 22, 2020].

[64] Getty Images, "Industry 4.0" [Online]. Available: https://www.gettyimages.com/detail/illustration/simple-set-of-industry-40-related-vector-royalty-free-illustration/1187860522 [Accessed: Aug. 22, 2020].

[65] Getty Images, "Internet of Things" [Online]. Available: https://www.gettyimages.com/detail/illustration/internet-of-things-icon-setroyalty-free-illustration/1156691042 [Accessed: Aug. 22, 2020].

[66] Getty Images, "Internet of Things infographic design" [Online]. Available: https://www.gettyimages.com/detail/illustration/internet-of-things-relatedline-infographic-royalty-free-illustration/1141680060 [Accessed: Aug. 22, 2020]. 
[67] Getty Images, "Technology and devises" [Online]. Available: https://www.gettyimages.com/detail/illustration/internet-of-things-icon-setroyalty-free-illustration/1156691042 [Accessed: Aug. 22, 2020].

[68] K. Omar and J. M. Gómez, "A selection model of ERP system in mobile ERP design science research: Case study-Mobile ERP usability," In Proceedings of the 13th International Conference of Computer Systems and Applications (AICCSA), Agadir, Morocco, November 29 - December 2. IEEE, 2016.

[69] F. D. Capua, S. Tan, and A. Wilkins, "Magic Quadrant for SAP S/4HANA application services," Gartner [Online]. Available: https://www.pwc.com/gx/en/about-pwc/analyst-relations/assets/magicquadrant-sap-s4hana-may-20-2019.pdf, 2019, [31st August, 2020].

[70] A. Banerjee, "Blockchain with IOT: Applications and use cases for a new paradigm of supply chain driving efficiency and cost," Advances in Computers, vol. 115, pp. 259-292, 2019.

[71] E. Labonte-LeMoyne, P.-M. Leger, J. Robert, G. Babin, P. Charland, and J.-F. Michon, "Business intelligence serious game participatory development: Lessons from ERPsim for big data," Business Process Management Journal, vol. 23, no. 3, pp. 493-505, 2017.

[72] D. L. Olson, B. Johansson, and R. A. D. Carvalho, "Open source ERP business model framework," Robotics and Computer-Integrated Manufacturing, vol. 50, pp. 30-36, 2015.

[73] M. Guay, "State of North Carolina JLOC on IT," Gartner [Online]. Available:

https://www.ncleg.gov/DocumentSites/committees/JLOCIT//03-082018/State\%20of\%20NC\%20ERP\%20Briefing-Ver-3.pdf [Accessed: Aug. 22, 2020].

[74] P. C. Franks, Records and Information Management. Chicago: American Library Association, 2013.

[75] S. Katuu, "Exploring the challenges facing archives and records professionals in Africa: Historical influences, current developments and opportunities. The UNESCO Memory of the World Programme: Key aspects and recent developments, R. Edmondson, L. Jordan, and A. C. Prodan, Eds. Switzerland: Springer Nature, 2020, pp. 275-292. 